J. Lake Sci.(湖泊科学), 2009, 21(4): 490-494

http://www.jlakes.org. E-mail: jlakes@niglas.ac.cn

(C2009 by Journal of Lake Sciences

\title{
太湖越冬蓝藻空间分布的初步研究*
}

\author{
季 健, 孔繁翔**, 于 洋, 张 民, 阳 振, 钱善勤, 吴晓东
}

(中国科学院南京地理与湖泊研究所, 南京 210008)

摘 要: 为确定 2007-2008 年冬季蓝藻在太湖各个湖区的分布及其变化规律，在冬季逐月对太湖主要湖区 14 个位点采集底泥 和水样, 应用苂光分析法测定样品中藻蓝素含量, 以确定冬季太湖各个湖区的藻蓝素分布状况, 比较冬季太湖各个湖区水体 和底泥中蓝藻的分布差异. 实验结果说明与夏季情况不同, 相对于西南太湖水域, 2007-2008 年冬季北太湖水体和底泥中的蓝 藻含量均较低, 而西南湖区部分区域 12 月仍出现了蓝藻的聚集, 底泥表面的藻蓝素含量也较高, 说明调查期间, 冬季越冬蓝 藻主要分布于西太湖和南太湖。

关键词: 越冬蓝藻; 藻蓝素; 菼光分析法; 空间分布; 太湖

\section{Spatial variations of the over-winter cyanobacterial in Lake Taihu}

\author{
JI Jian, KONG Fanxiang, YU Yang, ZHANG Min, YANG Zhen, QIAN Shanqin \& WU Xiaodong
}

(Nanjing Institute of Geography and Limnology, Chinese Academy of Sciences, Nanjing 210008, P.R.China)

\begin{abstract}
In order to investigate the spatial variations of the over-winter cyanobacteria in different areas of Lake Taihu, sediment and water samples were collected monthly in 14 sites in winters from 2007 to 2008. The phycocyanobilin concentration (PC) of samples was measured by the fluorometry analysis of pigments to confirm the difference of PC's spatial variations among three areas of Lake Taihu. The result shows that, differing from summer, the winter PC in both sediment and water from northern part was lower than western and southern part of Lake Taihu. Even in December, in some parts of western and southern areas the cyanobacteria was still blooming, and PC of surface sediment was also high. According to the result, it is clear that the over-winter cyanobacteria was mainly distributed in western and southern areas of Lake Taihu during the investigation winter seasons.

Keywords: The over-winter cyanobacteria; phycocyanobilin; fluorometry; spatial variations; Lake Taihu
\end{abstract}

许多生物会采取策略来避开不利于生长的恶劣条件 ${ }^{[1]}$. 或者形成狍子, 或者形成休眠体来越冬甚至 渡过更长的时间. 水华蓝藻微囊藻虽然不能形成特殊形态的休眠细胞, 但秋冬季时也会在底泥中聚集, 以度过一段不利于生长的时期 $[2-4]$. Preston et al用 ${ }^{15} \mathrm{~N}$ 稳定同位素示踪的方法显示夏季水体中蓝微囊藻的 群体来自于越冬底泥中的蓝微囊藻群体 ${ }^{[5]}$. 这种位于沉积物中的蓝藻群体聚集可能为次年蓝藻的生长提 供种源, 甚至可能成为蓝藻大量增长的重要来源 ${ }^{[6-7]}$.

目前关于越冬蓝藻的理论研究主要关于蓝藻的越冬对于次年水体蓝藻生物量的贡献 ${ }^{[8-11]}$, 着重研究 蓝藻的垂直迁移以及复苏对于次年夏季蓝藻水华构成的影响，一般都是基于深水湖泊蓝藻越冬复苏的研 究, 只有很少的研究是基于浅水湖泊 ${ }^{[7,11-12]}$. 对我国广泛分布的大型浅水湖泊, 不仅仅要了解其复苏和形 成水华的过程, 更要提前知道, 蓝藻是在哪个湖区的底泥表面越冬, 以及来年春季最有可能在哪个湖区 最先复苏, 形成最早的蓝藻水华, 以便采取具有针对性的措施, 去除越冬蓝藻, 尽可能控制夏季蓝藻水 华的强度. 关于太湖这类大型浅水湖泊中越冬蓝藻的空间分布还未有报道. 了解冬季蓝藻的空间分布特

* 江苏省太湖水污染治理科技专项(BK2007748)和 973 计划 “大中型浅水湖泊蓝藻水华暴发机理研究” (2008CB418000)联合 资助. 2008-10-06 收稿; 2008-10-31 收修改稿. 季健, 男, 1983 年生, 硕士研究生; E-mail: mossjj@163.com.

** 通讯作者; E-mail: fxkong@niglas.ac.cn. 
征, 对于次年蓝藻水华控制和预测预警有着重要的意义. 太湖作为一个浅水湖泊, 有着强烈水体扰动, 使得蓝藻的越冬分布更为复杂, 本研究对 2007-2008 年太湖越冬蓝藻的空间分布进行了调查, 初步确定 了太湖不同湖区越冬蓝藻的空间分布特征，为寻找蓝藻越冬时空分布与来年水华发生过程的关系提供背 景数据.

\section{1 材料和方法}

\section{1 样品采集}

2007 年 10 月至 2008 年 3 月每月在太湖采样(图 1). 根据夏季蓝藻水华的分布, 把太湖划分为 3 个采 样区域: 北太湖, 西太湖, 中南太湖, 设立 14 个采样点. 用柱状采泥器采取底泥, 然后选取 $0-2 \mathrm{~cm}$ 作为表 层样, $0^{\circ} \mathrm{C}$ 下保存. 用 $2.5 \mathrm{~m}$ 长的 $\mathrm{PVC}$ 柱状采水器采集整水柱, 混匀分装带回实验室, 并及时用多功能水质 仪(YSI6600-V2)(Yellow Spring Instruments, USA)测定水体溶解氧, 浊度, 叶绿素浓度, 水温, $\mathrm{pH}$, 电导率 等.

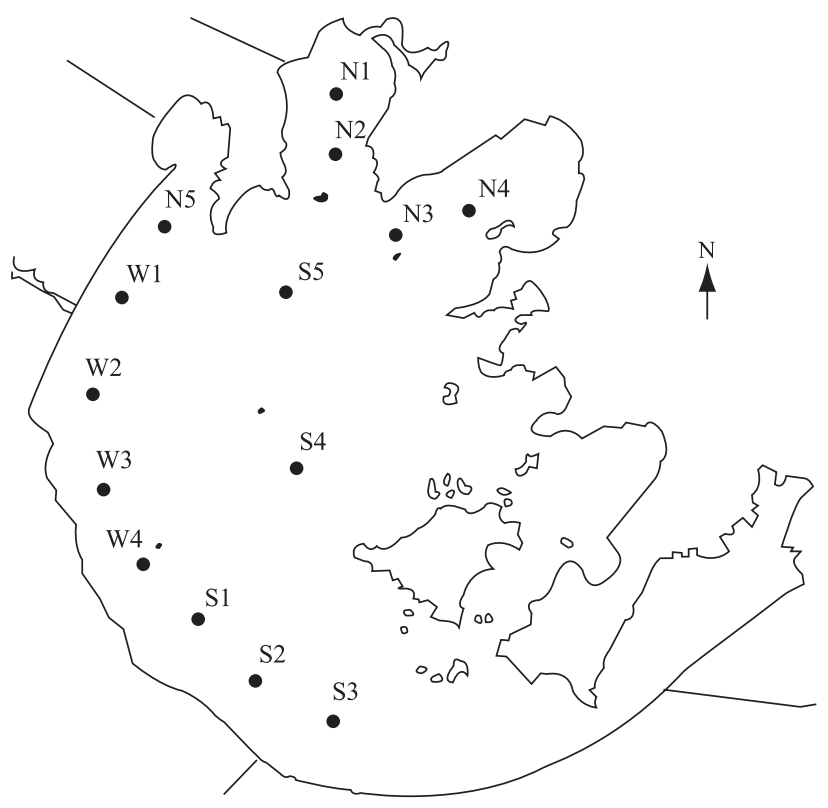

图 1 太湖采样点分布

Fig.1 The distributing of sampling sites in Lake Taihu

\section{2 样品前处理}

1.2 .1 水体中藻蓝素浓度的测定 取水样 $100 \mathrm{ml}$, 用 GF/C 滤膜过滤, 所得滤膜置于研针中仔细研 磨 2-5 min, 加人 $\mathrm{pH} 7.0$ Tris 缓冲液 $3 \mathrm{ml}$, 然后转 移离心管中, $4^{\circ} \mathrm{C}$ 下避光保存 $8-10 \mathrm{~h}$, 然后再 $4000 \mathrm{r} / \mathrm{min}$ 下离心 $5 \mathrm{~min}$, 将上清液转移, 定容. 1.2 .2 底泥表面藻蓝素含量的测定称取一定量 解冻后的底泥表层样品, 室内风干后称重, 测定 含水率, 计算底泥干重; 另称取一定量底泥样品, 放置于研钵中, 加人 $\mathrm{pH}$ 7.0 Tris 缓冲液, 每个样 品仔细研磨 2-5min, $4^{\circ} \mathrm{C}$ 避光静置 $8-10 \mathrm{~h}$, 然后 在 $4000 \mathrm{r} / \mathrm{min}$ 下离心 $5 \mathrm{~min}$. 将上清转移, 定容.

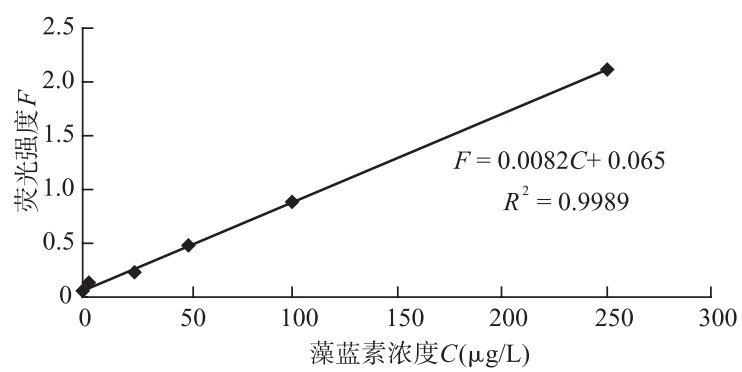

图 2 藻蓝素的标准曲线

Fig.2 F-C standard curve of phycocyanobilin 


\section{3 藻蓝素测定}

藻蓝素的测定用岛津苂光分光光度计 RF-5301，测定条件采用激发波长为 $620 \mathrm{~nm}$, 发射波长 $647 \mathrm{~nm}^{[13-14]}$ ，扫描速度设为 $60 \mathrm{~nm} / \mathrm{min}$ ，激发和发射光栅宽度均设为 $5 \mathrm{~nm}$ ，响应时间 $2.0 \mathrm{~s}, \mathrm{PM}$ 增益置于

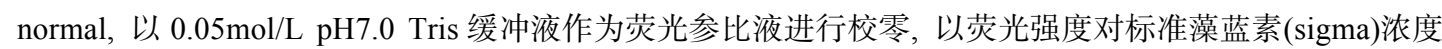
做出标准曲线, 见图 2. 在标准系列相同条件下测定样品的苂光强度从而得知样品中藻蓝素的含量.

\section{2 结果与讨论}

\section{1 太湖水质参数的月变化}

采样期间太湖水质参数变化如图 3 , 人冬后水温由 $15^{\circ} \mathrm{C}$ 逐渐降至 $4^{\circ} \mathrm{C}, 1$ 月水温最低, 2 月开始逐步上 升. $\mathrm{pH}$ 一直都处于一个弱碱性的水平, 2 月份的值为最低, 仍高于 8.0. 溶解氧水平相对稳定, 保持大于 $7.5 \mathrm{mg} / \mathrm{L}$ 的水平.

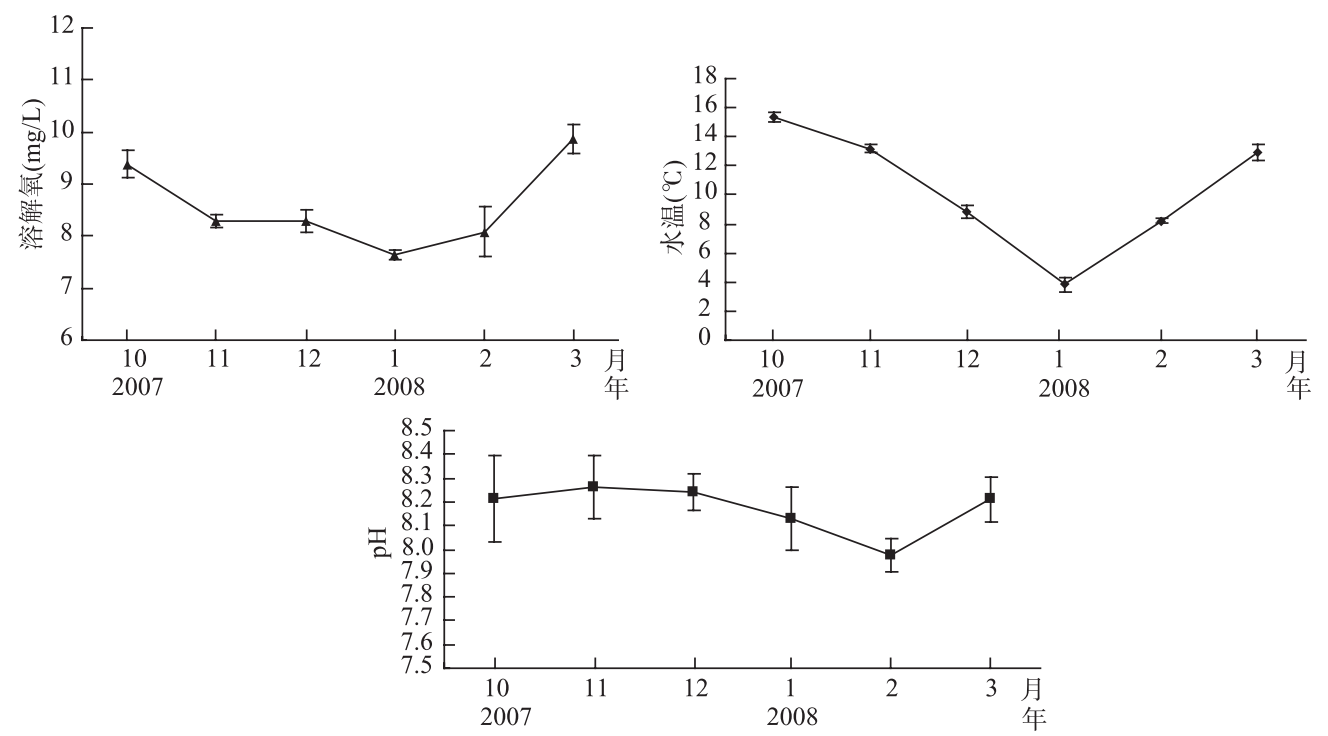

图 3 太湖水体中溶解氧, 水温和 $\mathrm{pH}$ 的月变化

Fig.3 Monthly changes of dissolved oxygen, water temperature and $\mathrm{pH}$

\section{$2.22007-2008$ 年太湖越冬蓝藻的空间分布特征}

2.2.1 太湖不同湖区底泥表面藻蓝素含量检测 由于太湖水体和底泥中很少发现隐藻和红藻 ${ }^{[15-16]}$, 而藻蓝 素只存在于蓝藻, 隐藻和红藻之中, 因而在太湖藻蓝素含量可以近似代表蓝藻的相对含量 ${ }^{[13]}$. 各个采样 点底泥样品以及水体中藻蓝素测定结果见图 4.

人冬后, 北太湖梅梁湾等湖区中底泥中蓝藻含量较少, 且相对稳定, 保持在 10-30ng/g 的浓度范围内, 在南太湖以及西太湖含量较多. 西太湖以及南太湖部分区域底泥藻蓝素含量则有较大波动, 月际差异大. 整个采样周期中, 各个位点在 1 月间, 均出现一个明显的下降的趋势，此时北太湖位于梅梁湾的 N1 和 N2 底泥中蓝藻含量下降到无法检测到的水平. 到 2 月份, 各个湖区底泥蓝藻的含量有所增加, 以西南湖区 最为显著. 西太湖和南太湖湖区的采样点 W2、W4、S1、S4 底泥表面的越冬蓝藻累计含量最高, 而夏季 蓝藻水华十分严重的梅梁湾和贡湖湾的底泥中蓝藻的累计含量却相对较低.

2.2.2 太湖不同湖区水体中藻蓝素含量检测 在不同湖区的水体中, 11 月各湖区蓝藻含量较为平均, 北太 湖, 南太湖, 西太湖均有较多蓝藻分布. 至 12 月, 全太湖的蓝藻含量显著减少, 只在西太湖和南太湖部 分湖区如 W1、S1、S5 偶尔出现蓝藻聚集，堆积点的浓度甚至高达 $150 \mu \mathrm{g} / \mathrm{L} ， 几$ 乎与夏季蓝藻暴发区域的 浓度水平相似. 而 1 月太湖所有采样点的水体蓝藻藻蓝素的量急剧减少, 平均减至 $10 \mu \mathrm{g} / \mathrm{L}$ 以下. 这可能 
与调查期间太湖区域发生的多年不见的强降温降雪天气有关. 2 月持续一个月较低的蓝藻含量. 3 月西太 湖偏南的区域以及南太湖蓝藻开始增加, 而北太湖含量较低, 未有显著的变化.

张晓峰等 ${ }^{[17]}$ 在 2003-2005 年期间对梅梁湾的调查研究发现, 底泥表面的藻蓝素含量在每年 3、4 月份 达到最大值; 随后则呈下降趋势，至 9 月份降至全年最低点; 10 月底泥表面的藻蓝素含量又逐步上升，这 可能是由于当冬季环境温度低、光照弱时, 夏季形成水华的微囊藻群体开始解体为小群体, 比重加大, 特 别容易由水体下沉到底泥表面; 而进入春季 (3、4 月份)后在温度和光照等外界适宜条件下，在底泥中越冬 的蓝藻逐渐从底泥表面重新悬浮, 进人水体复苏, 导致底泥表面蓝藻生物量下降. 本次研究对于太湖越 冬蓝藻分布的调查中发现, 所进行调查的采样点, 底泥表面的蓝藻含量从 11 月到 12 月确实有所增加, 1 月迅速下降后, 3 月即又开始增加. 这与已有的研究所发现的规律基本一致. 但是 Tsujimura 等[7]研究了日 本琵琶湖沉积物中的微囊藻群体的季节变化, 发现底泥表面的蓝藻含量在夏季和秋季时是一个增长的过 程，而从 10 月到 12 月是一个减少的过程，推测其原因是由于温度的下降和光照的不足造成蓝藻的死亡， 从 12 月至次年 6 月, 底泥蓝藻含量继续减少. 太湖的调查结果与已有淡水浅水湖泊冬季底泥蓝藻含量变 化有所差异, 推测其原因, 可能是由于太湖所处较低纬度, 没有冰封期, 浅水湖泊没有温跃层, 即使在 12 月, 水体存有大面积蓝藻群体聚集, 从而能够保持蓝藻从水体向底泥中迁移. 而 3 月初, 水温已回升接近 $14^{\circ} \mathrm{C}$, 达到越冬蓝藻复苏的温度阈值 ${ }^{[18]}$, 底泥表层蓝藻的量开始增加, 然后上升进人水体开始复苏.
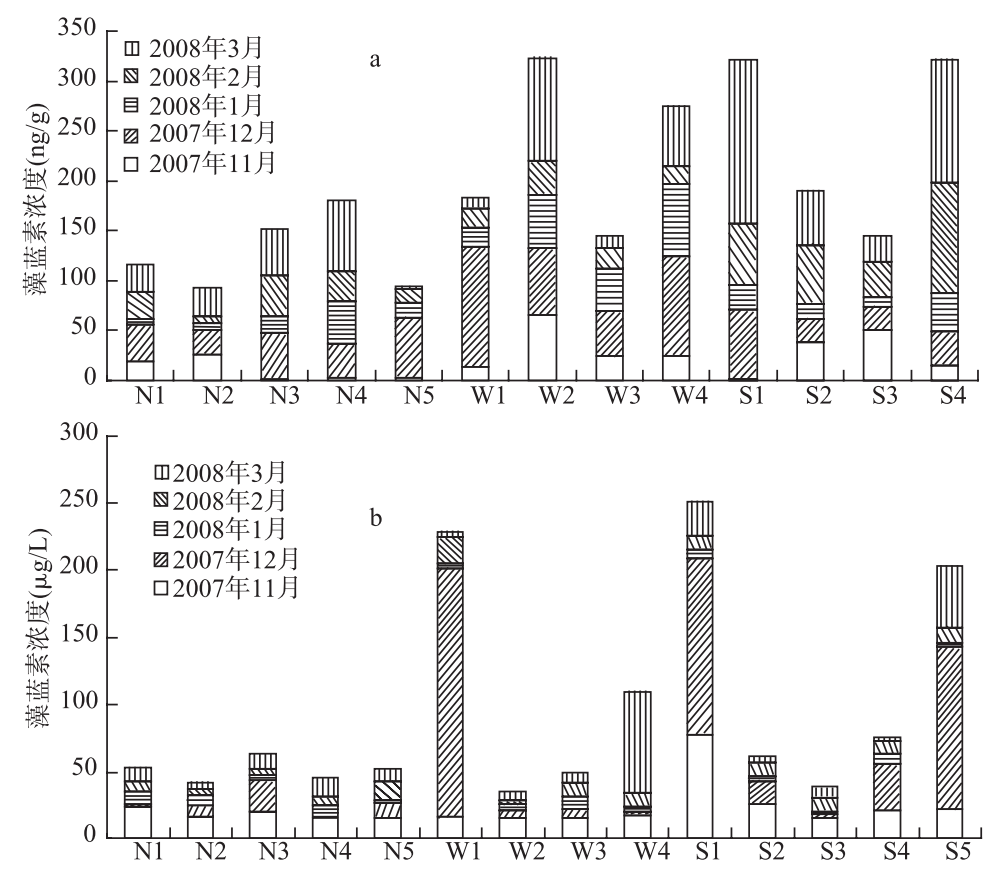

图 42007 年 11 月至 2008 年 3 月表层底泥样品(a)和水样中(b)藻蓝素浓度

Fig.4 PC in the surface sediments(a) and in water column(b) from Nov. 2007 to Mar. 2008

由于太湖平均水深 $2 \mathrm{~m}$ 左右, 又处于亚热带季风气候区, 受冬季盛行风向的影响, 整个西太湖和南太 湖受到水体的扰动作用较为剧烈. 在浅水湖泊中, 沉积物表面蓝藻的上浮主要是由风力引起的水力扰动 形成的被动过程 ${ }^{[1]}$. 此次 11 月、 12 月、 1 月三次采样期间, 采样点的平均风速超过 $7 \mathrm{~m} / \mathrm{s}$, 因而各个采样 点的底泥中蓝藻的含量变化受到水力扰动的干扰较为严重, 月际间底泥蓝藻含量的不连续性也体现了扰 动的结果. 此前, 已有关于水文气象条件与夏季蓝藻水华在不同湖区之间输移通量的关系的研究报道, 而此次调查观测到水文气象与越冬蓝藻同样密切相关的现象, 因此有必要对水文气象条件与不同湖区中 越冬蓝藻含量变化的定量关系进行深人研究. 
Brunberg 等在 2002 年报道只有极端气候比如缺水和冰冻对于越冬蓝藻才具有较大伤害, 导致其急剧 减少 ${ }^{[19]}$. 在本次采样周期中, 2008 年 1 月采样正遇到一次多年不见的强降雪降温过程，水温从 $8^{\circ} \mathrm{C}$ 迅速降 至不足 $4^{\circ} \mathrm{C}$, 无论水体还是底泥中的蓝藻含量都急剧减少，水体蓝藻含量整体降至 $10 \mu \mathrm{g} / \mathrm{L}$ 以下，而底泥 受影响略小, 但各个位点蓝藻也均有减少. 参考相关卫星遥感图片, 降雪前仍在水面大面积聚集的蓝藻 群体在降雪过程之后迅速消失，这表明极端气候是冬季蓝藻群体迅速消失的主因，其机理还有待于进一 步研究.

综合采样周期水体和底泥中蓝藻含量的变化, 太湖冬季蓝藻分布主要位于西太湖和南太湖的部分区 域，以西太湖的 W1, W2, W4 以及南太湖的 S4 为典型，可以认为这些水域是 2007 年至 2008 年蓝藻越冬 的主要水域.

\section{3 参考文献}

[1] Reynolds CS. The ecology of freshwater phytoplankton. Cambridge: Cambridge University Press, 1984: 384.

[2] Reynolds CS, Rogers DA. Seasonal variations in the vertical distribution and buoyancy of Microcystis aeruginosa Kütz. emend Elenkin in Rostherne Mere, England. Hydrobiologia, 1976, 48: 17-23.

[3] Fallon RD, Brock TD. Overwintering of Microcystis in Lake Mendota. Freshwater Biol, 1981, 11: 217-226.

[4] Takamura N, Yasuno M, Sugahara K. Overwintering of Microcystis aeruginosa Kütz. in a shallow lake. J Plankton Res, 1984, 6: 1019-1029.

[5] Preston T, Stewart WDP, Reynolds CS. Bloomforming cyanobacterium Microcystis aeruginosa overwinters on sediment surface. Nature, 1980, 288: 365-367.

[6] Boström B, Pettersson AK, Ahlgren I. Seasonal dynamics of a cyanobacteria-dominated microbial community in surface sediments of a shallow, eutrophic lake. Aquat Sci, 1989, 51: 153-178.

[7] Tsujimura S, Tsukada H, Nakahara H et al. Seasonal variation of Microcystis populations in sediments of Lake Biwa, Japan. Hydrobiologia, 2000, 434: 183-192.

[8] Hansson LA, Rudstam LG, Johnson TB et al. Patterns in algal recruitment from sediment to water in a dimictic, eutrophic lake. Can J Fish Aquat Sci, 1994, 51: 2825-2833.

[9] Head RM, Jones RI, Bailey AE. An assessment of the influence of recruitment from the sediment on the development of planktonic populations of cyanobacteria in a temperate mesotrohic lake. Freshwater Biol, 1999, 41: 759-769.

[10] Brunberg AK, Blomqvist P. Recruitment of Microcystis from lake sediments: the importance of littoral inocula. J Phycol, 2003, 39: $58-63$.

[11] Jolanda MH Verspagen, Eveline OFM Snelder, Petra M Visser et al. Recruitment of benthic microcystis (cyanophyceae) to the water column: internal buoyancy changes or resuspension. J Phycol, 2004, 40: 260-270.

[12] Irene Karlsson Elfgren, Brunberg AK. The importance of shadow sediments in the recruitment of Anabena and Aphanizomenon (cyanophyceae). J Phycol, 2004, 40: 831-836.

[13] 阎 荣, 孔繁翔, 韩小波. 太湖底泥表层越冬藻类群落动态的菼光分析法初步研究. 湖泊科学, 2004, 16(2): 163-167.

[14] Abalde J, Betancourt L, Torres E et al. Purification and characterization of phycocyanin from marine cyanobacterium Synechococcus sp.. Plant Sci, 1998, 136: 109-120.

[15] 翟文川, 潘红坌. 太湖蓝藻中天然色素的分离提取及测定. 湖泊科学, 1997, 9(3): 284-285.

[16] 陈宇炜，高锡芸，秦伯强. 西太湖北部夏季藻类种间关系的初步研究. 湖泊科学, 1998, 10(4): 35-40.

[17] 张晓峰, 孔繁翔, 曹焕生等. 太湖梅梁湾水华蓝藻复苏过程的研究. 应用生态学报, 2005, 16(7): 1346-135.

[18] 陶 益, 孔繁翔, 曹焕生等. 太湖底泥水华蓝藻复苏的模拟. 湖泊科学, 2005, 17(3): 231-236.

[19] Brunberg AK, Blomqvist P. Benthic overwintering of Microcystisis colonies under different environmental conditions. $J$ Plankton Res, 2002, 24: 1247-1252. 